\section{A) Check for updates}

Cite this: Food Funct., 2021, 12, 3992

\title{
Anredera cordifolia extract enhances learning and memory in senescence-accelerated mouse-prone 8 (SAMP8) mice
}

\author{
Eri Sumiyoshi, (D) a Michio Hashimoto, ${ }^{\text {a }}$ Shahdat Hossain, (D) a,b \\ Kentaro Matsuzaki, (DD a Rafiad Islam, (D) a Yoko Tanabe, ${ }^{a}$ Koji Maruyama, ${ }^{c}$ Koji Kajima, ${ }^{c}$ \\ Hiroyuki Arai, ${ }^{d}$ Yasushi Ohizumi ${ }^{e}$ and Osamu Shido ${ }^{a}$
}

\begin{abstract}
Learning and memory impairment may result from age-related decline in synaptic plasticity-related proteins in the hippocampus. Therefore, exploration of functional foods capable of ameliorating memory and cognition decline is an interesting endeavor in neuroscience research. We report the effects of Anredera cordifolia (AC) extract on learning and memory deficits in a senescence-accelerated mouse-prone 8 (SAMP8) mouse model, which demonstrate age-related memory deficits and related pathological changes in the brain. After 8 weeks of oral administration of AC extract, the mice were trained in the Novel Object Recognition (NOR) task, and after 7 more weeks, in the Morris Water Maze (MWM) task. Following the completion of behavioral testing, the blood biochemistry parameters, the hippocampal levels of brain-derived neurotropic factor (BDNF), PSD95, and NR2A, and the p-cAMP-response element binding ( $p$-CREB)/CREB ratio were measured. The AC-treated group spent more time exploring the novel objects in the NOR task, and showed faster acquisition and better retention in the MWM task than the negative control (CN) group. In addition, AC enhanced the levels of the aforementioned neuronal plasticity-related proteins, and did not affect the blood biochemistry parameters. Therefore, our data suggest that the AC extract may improve learning and memory without causing any noticeable side effects in the body.
\end{abstract}

Received 14th December 2020 Accepted 15th March 2021

DOI: $10.1039 / \mathrm{dOfo} 03272 \mathrm{~g}$

rsc.li/food-function ing glutamic pyruvic transaminase (GPT) and glutamate oxaloacetate transaminase (GOT) ${ }^{8-10}$ These studies have, however, focused mainly on activities rather than the cognitive function underlying learning and memory. On one hand, the increased prevalence of diabetes, hypertension, and cardiovascular diseases in the modern era is a risk factor for chronic anxiety and depression in the adult population; on the other hand, these disorders, on which AC extract exerts ameliorating effects, are also risk factors for many age-related diseases, such as Alzheimer's disease (AD) and dementia. Recently, Nakajima et $a .^{11}$ have reported that AC extract administration improved MK-801-induced memory impairment in mice. As a mechanism, the AC extract may have been involved in activating the cAMP-response element binding protein (CREB)/cAMPresponse element (CRE) pathway in vitro. ${ }^{12}$ Furthermore, adenosine and its derivative, cordysinin $\mathrm{B}$, might be active ingredients in AC because of their ability to regulate CRE-mediated transcription (unpublished observation). However, the effect of chronic AC extract administration on cognitive function in agerelated learning and memory disorders, such as in senescenceaccelerated mouse-prone 8 (SAMP8) mice, is unknown; therefore, we investigated the effects of AC extract administration on learning and memory in a SAMP8 mouse model using the 
Novel Object Recognition (NOR) and Morris Water Maze (MWM) tasks.

Aging is the main risk factor for learning and memory impairment, as seen in degenerative $\mathrm{AD} .{ }^{13}$ Therefore, in order to understand the mechanisms that interfere with aging and/ or to prevent or treat chronic neural diseases associated with aging, oral ${ }^{14}$ and intracerebroventricular administration ${ }^{15}$ of numerous synthetic and herbal compounds have been used in various animal models to date. SAMP8 mice represent an interesting and advantageous nontransgenic mouse model for AD research. ${ }^{16}$ These mice exhibit phenotypes of accelerated aging, ${ }^{17}$ including age-related impairment in learning and memory, ${ }^{18}$ and demonstrate neuropathological changes of the synapses analogous to cognitive dysfunction in $\mathrm{AD} .{ }^{19}$ More importantly, SAMP8 mice exhibit impairment of performance in hippocampus-dependent tasks, such as the NOR task ${ }^{20-22}$ and the MWM task. ${ }^{23,24}$ The NOR task and the MWM task have contributed greatly to our understanding of the relationship between synaptic plasticity, behavior, and $N$-methyl-Daspartate receptors (NMDARs) in hippocampal neurons. ${ }^{25,26}$ Learning in the MWM task relies on distal environmental cues to swim from the starting locations around the perimeter of an open swimming arena to locate a submerged escape platform. Spatial learning is assessed through repeated trials, while spatial memory is determined by the preference for the remembered escape platform area when the platform itself is absent. SAMP8 mice show inadequacy in long-term potentiation (LTP), ${ }^{27-29}$ the neurochemical foundation of learning and memory. Moreover, lower levels of brain-derived neurotrophic factor $(\mathrm{BDNF})^{30-32}$ and postsynaptic density protein 95 (PSD95) $^{31,33}$ in SAMP8 mice lead to decreased activation of $\mathrm{CREB}^{33}$ and dysfunction of NMDAR, ${ }^{34}$ indicating that BDNF-NMDAR-PSD95-CREB-mediated synaptic plasticityrelated signaling is impaired in these mice. No studies have yet been focused on the role of AC extract in an age-related animal model with learning and memory impairment, or especially the effects of AC extract on synaptic plasticity-related proteins, such as the levels of BDNF, PSD95, NR2A, and the $\mathrm{p}$-CREB/CREB ratio in the hippocampus. The purpose of the current investigation was three-fold: (i) to determine whether oral administration of AC extract affected learning and memory in the age-accelerated SAMP8 mice; if so, then, (ii) to elucidate the mechanisms of action of AC extract; and with regard to food safety concern, (iii) to determine whether AC extract produces any side effects in SAMP8 mice.

\section{Materials and methods}

\subsection{Extract of Anredera cordifolia (AC)}

In this study, we made powder from the prophyll of the Anredera cordifolia (AC) plant (Sankyo Holdings Co., Ltd, Fuji, Japan). Ten grams of dried AC powder was mixed with $1000 \mathrm{~mL}$ of methanol and boiled at $100{ }^{\circ} \mathrm{C}$ for $5 \mathrm{~min}$. Subsequently, the extract solution was filtered, and methanol was distilled under reduced pressure to yield a dried extract.
The dried extract was redissolved in $1000 \mathrm{ml}$ of distilled water. $\mathrm{AC}$ extract was administered through drinking water at a dose of $10 \mathrm{mg} \mathrm{mL}{ }^{-1}$ water. $^{10}$ The average particle size of the final powder was $9.083 \mu \mathrm{m}$. Particle size measurement was outsourced (Seishin Enterprise CO., Ltd, Tokyo, Japan) and measured using a laser diffraction/scattering particle size distribution analyzer (LMS-2000e; Seishin Enterprise CO., Ltd).

\subsection{Animals}

Fifteen-week-old male SAMP8 mice, purchased from Japan SCL Inc. (Hamamatsu, Japan), were individually housed and maintained in an animal facility under a $12 \mathrm{~h} / 12 \mathrm{~h}$ light-dark cycle at $24.2 \pm 1.0^{\circ} \mathrm{C}$. The mice were fed a commercially available MF diet (Oriental Yeast Co., Ltd, Tokyo, Japan), and water was supplied ad libitum. This study was conducted in accordance with the Guidelines for Animal Experimentation of Shimane University, compiled from the Guidelines for Animal Experimentation of the Japanese Association for Laboratory Animal Science and the experiments were approved by the Animal Experiment Committee of Shimane University (approval number: IZ29-46).

\subsection{Experimental schedule}

After 1 week of acclimatization to the laboratory conditions, the mice were randomly divided into $\mathrm{AC}$ extract $(\mathrm{AC} ; n=9)$ and tap water control $(\mathrm{CN} ; n=10)$ groups. AC extract was orally administered for 31 weeks until the completion of all behavioral experiments. Each week, we measured the body weight (BW) and water and food consumption of all mice. Drinking water containing the AC extract was freshly prepared and replaced every other day in the morning. After 8 weeks of treatment, the SAMP8 mice (age of 23 weeks) were subjected to the NOR test. Seven more weeks after performing the NOR task, mice (aged 30 weeks) were subjected to the locomotor activity test, MWM task training, and cued trial.

All behavioral tests were performed at the same time each day and by the same individual, who was blinded to the animal treatment group. The testing room was temperatureand humidity-controlled, with even illumination. All behavioral tests were recorded with a video camera (iVIS HF R800, Canon, Tokyo, Japan) and analyzed using motion analysis software (Kinovea, version 8.25, available for download at http:// www.kinovea.org).

\subsection{Novel object recognition (NOR) task}

The NOR task were carried out in an area $(25(\mathrm{~L}) \times 42(\mathrm{~W}) \times 20$ $(\mathrm{H}) \mathrm{cm}$ ) constructed of plastic. The objects used in this study were $3 \times 6 \times 3 \mathrm{~cm}$ blocks of equal size, but of different shapes, colors, and materials. The NOR task consisted of three sessions: the habituation, the familiarization, and the test session. In the habituation session, mice were habituated to an empty apparatus for $10 \mathrm{~min}$ a day for 2 consecutive days. During the familiarization session, the mice were exposed to two identical objects (A1 and A2), which they were allowed to explore for $5 \mathrm{~min}$. Twenty-four hours after the familiarization session, the mice were exposed to the familiar object and to a 
novel object (A1 and B), which they were allowed to explore for 5 min (test session). After the experiment, the total time spent exploring each of the two objects in the familiarization and test sessions was analyzed. The percentage of time spent exploring the novel object relative to the total time spent exploring both objects was calculated using the equation: Discrimination index (DI) $=$ novel object/[novel object + familiar object $] \times 100$. Thus, an index $>50 \%$ indicates novel object preference, $<50 \%$ indicates familiar object preference, and $50 \%$ implies no preference. ${ }^{35,36}$ Exploration of the objects was defined as sniffing or pointing toward the object with the nose at a distance of less than $1 \mathrm{~cm}$; however, sitting on the object was not considered exploration. ${ }^{36,37}$

\subsection{Locomotor activity test}

Open-field activity was monitored to assess the locomotor activity levels of the AC and $\mathrm{CN}$ groups. Open-field activity was measured in an acrylic circular chamber with a white circular sheet affixed to its bottom. Each mouse was placed at the center of the circular chamber and allowed to explore freely for $60 \mathrm{~s}$. Afterward, the total traveled distance $(\mathrm{cm})$, which is an index of locomotor activity, was calculated.

\subsection{Morris water maze (MWM) task}

The MWM task was performed in a plastic circular pool measuring $120 \mathrm{~cm}$ in diameter and $40 \mathrm{~cm}$ in depth. The pool was filled with water, kept at a steady-state temperature of 25.0 $\pm 2.0{ }^{\circ} \mathrm{C}$, and made opaque with skimmed milk powder (Fujifilm Wako Pure Chemical Corporation, Osaka, Japan) to prevent the mice from seeing the platform. The circular pool was divided into four quadrants (Q1, Q2, Q3, and Q4) by two lines crossing at the center of the pool. The escape platform was $11.5 \mathrm{~cm}$ in diameter $\times 11.0 \mathrm{~cm}$ high, painted white, and placed at the center of quadrant Q1, where it remained fixed throughout the trials. Posters, shelves, a rack, a table, fences, a mounted-video camera, and wires on the ceiling served as extra-maze environmental visual cues.

The MWM task was carried out for 8 consecutive days, three trials per day for the first 6 consecutive days (acquisition training). Each mouse was gently placed in the water facing the wall at the perimeter of the pool and away from each of the other three quadrants (Q2, Q3, and Q4). The animal was allowed to swim until it climbed on top of the platform. The escape latency was defined as the time until the mouse reached the platform. Since the location of the platform was not indicated directly, mice had to memorize the hidden platform location in relation to various extra-maze environmental cues. Therefore, this task assesses spatial learning and memory. When a mouse could not reach the platform within $60 \mathrm{~s}$, it was then placed on the platform by the experimenter. Upon either success or failure, the mouse was left on the platform for $15 \mathrm{~s}$, and then gently removed from the hidden platform. Later, the mouse was gently dried with a soft-towel and kept in an incubator at $37^{\circ} \mathrm{C}$ to recover, before being returned to the home cage.
The day following the last acquisition trial (day 7), the mice were given a probe trial for $60 \mathrm{~s}$ to assess spatial memory retention. For the probe trial the escape platform was removed and the animal was placed in the water $180^{\circ}$ from the original platform position. ${ }^{38}$ For the probe trial, the time spent in the target quadrant and the number of times the mouse crossed over the position at which the platform had been located were recorded to indicate the degree of memory consolidation after training.

The day following the probe trial (day 8), the mice began the cued trial, in which the escape platform was in the same location as in the acquisition training but made visible by protruding above the water level. Mice could easily reach the visible platform by aiming at the only visible thing in the pool. The cued trial was regarded as a control task of the acquisition training, as the mouse can perform this task without using its spatial cognitive ability. ${ }^{38,39}$

\subsection{Brain tissue preparation}

Following the completion of behavioral testing, the mice were deeply anesthetized using isoflurane, and their blood was drawn for biochemical assays. The hippocampus was then dissected from the whole brain, flushed with $\mathrm{N}_{2}$, and stored at $-80{ }^{\circ} \mathrm{C}$ for further analysis.

\subsection{Chemicals and antibodies}

Rabbit anti-PSD95 (\#3409) was procured from Cell Signaling Technology (Danvers, MA, USA). Rabbit anti-p-CREB (Ser133; \#9198), mouse anti-CREB (\#9104), mouse anti-NR2A (\#4205), mouse anti- $\beta$-actin (\#4967), and secondary antibodies (goat anti-rabbit IgG [\#7074] and horse anti-mouse IgG [\#7076]) for the western blot analysis were purchased from Cell Signaling Technology (Danvers).

\subsection{Biochemistry}

The blood cell components were measured using a KX-21NV (Sysmex, Hyogo, Japan). The plasma biochemical parameters, including GPT, GOT, $\gamma$-GTP, lipid profile, albumin, blood urea nitrogen (BUN), uric acid, and creatinine levels, were measured with an automated biochemical analyzer Spotchem EZ SP-4430 (Arkray, Kyoto, Japan), the Spotchem EZ Reagent Strip KENSHIN-2 (Arkray), and the Spotchem EZ Reagent Strip Kidney-3 (Arkray) according to the manufacturers' instructions.

\subsection{ELISA for BDNF assay}

Hippocampal tissues were homogenized with Tris-buffer $(\mathrm{pH}$ 7.4) and centrifuged at $800 \mathrm{~g}$ for $15 \mathrm{~min}$ at $4{ }^{\circ} \mathrm{C}$ to remove the unbroken tissue and debris. The homogenized samples were again centrifuged at $12000 \mathrm{~g}$ for $10 \mathrm{~min}$ at $4{ }^{\circ} \mathrm{C}$ to prepare cytosolic fractions. These fractions were analyzed with a BDNF Emax® Immuno Assay System (Promega, WI, USA) by ELISA as described previously, ${ }^{40}$ according to the manufacturer's protocol. The absorbance at $450 \mathrm{~nm}$ was measured using a plate reader (DTX880, Beckman Coulter, CA, USA), and the BDNF concentrations were calculated using a BDNF-calibration 
curve. The protein concentration was evaluated using a Pierce BCA Protein Assay Kit (Thermo Fisher Scientific, Waltham, MA, USA).

\subsection{Western blot analysis}

$\mathrm{N}_{2}$-Flushed hippocampal tissues were homogenized with a lysis buffer composed of $1 \mathrm{mM}$ EDTA, 1\% SDS, $1 \times$ complete protease inhibitor cocktail (Roche Diagnostics, Schweiz), 1× phosphatase inhibitor cocktail (Fujifilm Wako Pure Chemical Corporation), and $20 \mathrm{mM}$ Tris- $\mathrm{HCl}$ ( $\mathrm{pH}$ 7.4). After incubation on ice for $30 \mathrm{~min}$, the supernatant was collected by centrifugation at $13000 \mathrm{~g}$ for $15 \mathrm{~min}$ at $4{ }^{\circ} \mathrm{C}$. Proteins were separated on $10 \%$ Tris-HCl denaturing gels by SDS-PAGE and transferred onto polyvinyl difluoride membranes (Immobilon-P, Merck Millipore, Burlington, MA, USA), as described previously. $^{36,41-43}$ The membranes were blocked with $5 \%$ skimmed milk (Fujifilm Wako Pure Chemical Corporation), and incubated with primary antibodies $(1: 1000)$ overnight at $4{ }^{\circ} \mathrm{C}$, followed by washing five times with Tris-buffered saline. The HRP-conjugated secondary antibodies were detected using Amarsham ECL Prime Western detection reagent (GE Healthcare) and visualized using an Image Quant LAS-4000 biomolecular imager (FUJI FILM, Tokyo, Japan). The protein concentrations were measured using a Pierce BCA Protein Assay Kit (Thermo Fisher Scientific).

\subsection{Statistics}

Values are expressed as mean \pm standard error of the mean (SEM). Two tailed student's $t$-tests were used to measure the inter-group differences (Table 2 and Fig. 1C, D, 2B-D, 3) and intra-group differences (Fig. 1A and B). Two-way ANOVA [group $\times$ time] for repeated measures was used to examine any significant differences in variables during the intervention period (Table 1). This model was also used to examine significant
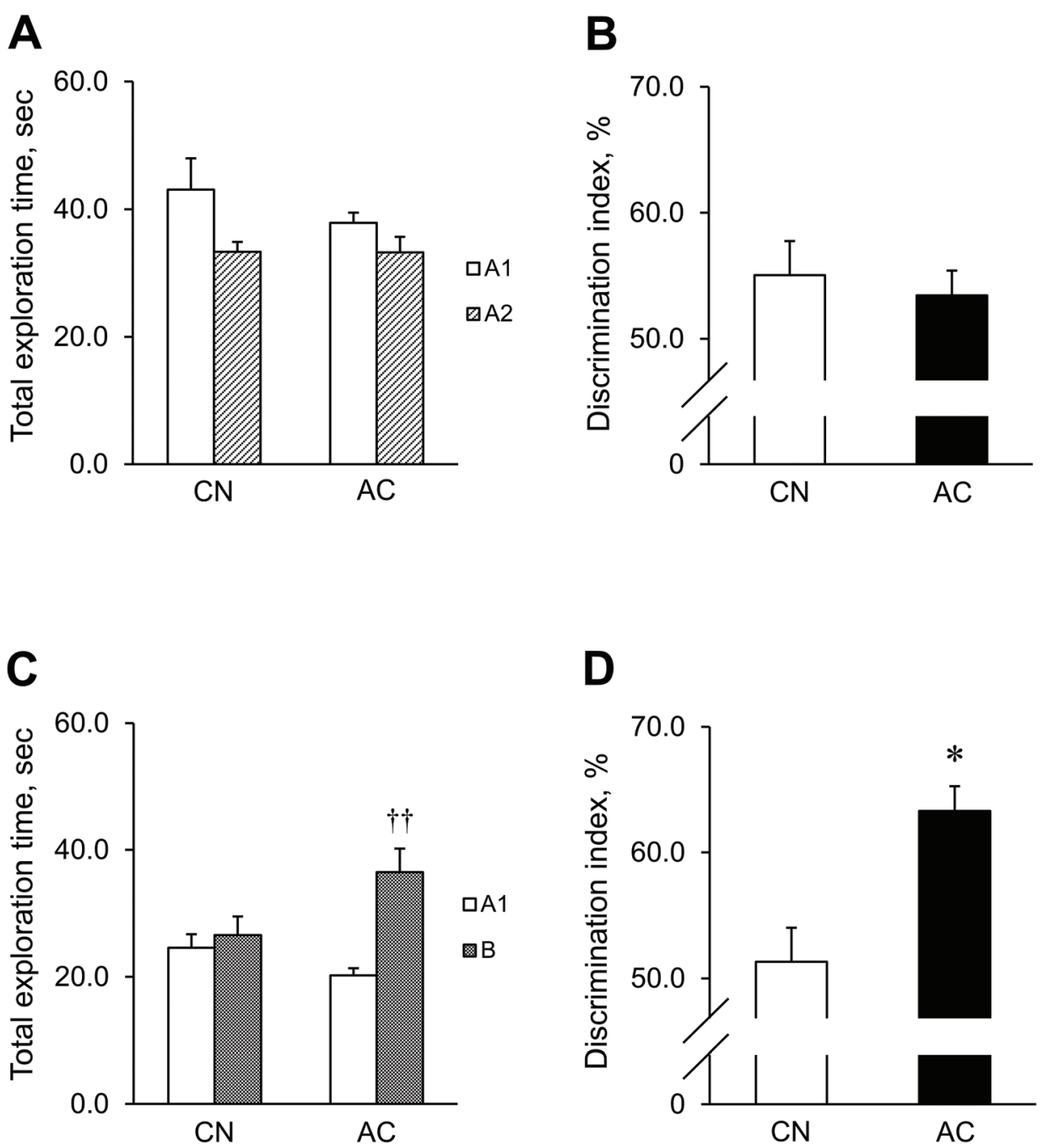

Fig. 1 Total exploration time of novel objects and discrimination index (DI) in the Novel Object Recognition (NOR) task. Graphs indicate mean \pm SEM for $10 \mathrm{CN}$ and $9 \mathrm{AC}$ mice. (A) Total exploration time for objects A1 and A2 and (B) DI for exploring objects A1 and A2 (familiarization session). (C) Total exploration time for objects $\mathrm{A} 1$ and $\mathrm{B}$ and (D) DI for exploring objects $\mathrm{A} 1$ and $\mathrm{B}$ (test session). $\dagger \dagger p<0.01$, compared to object $\mathrm{A} 1 .{ }^{*} p<0.05$, compared to the $\mathrm{CN}$ group. 

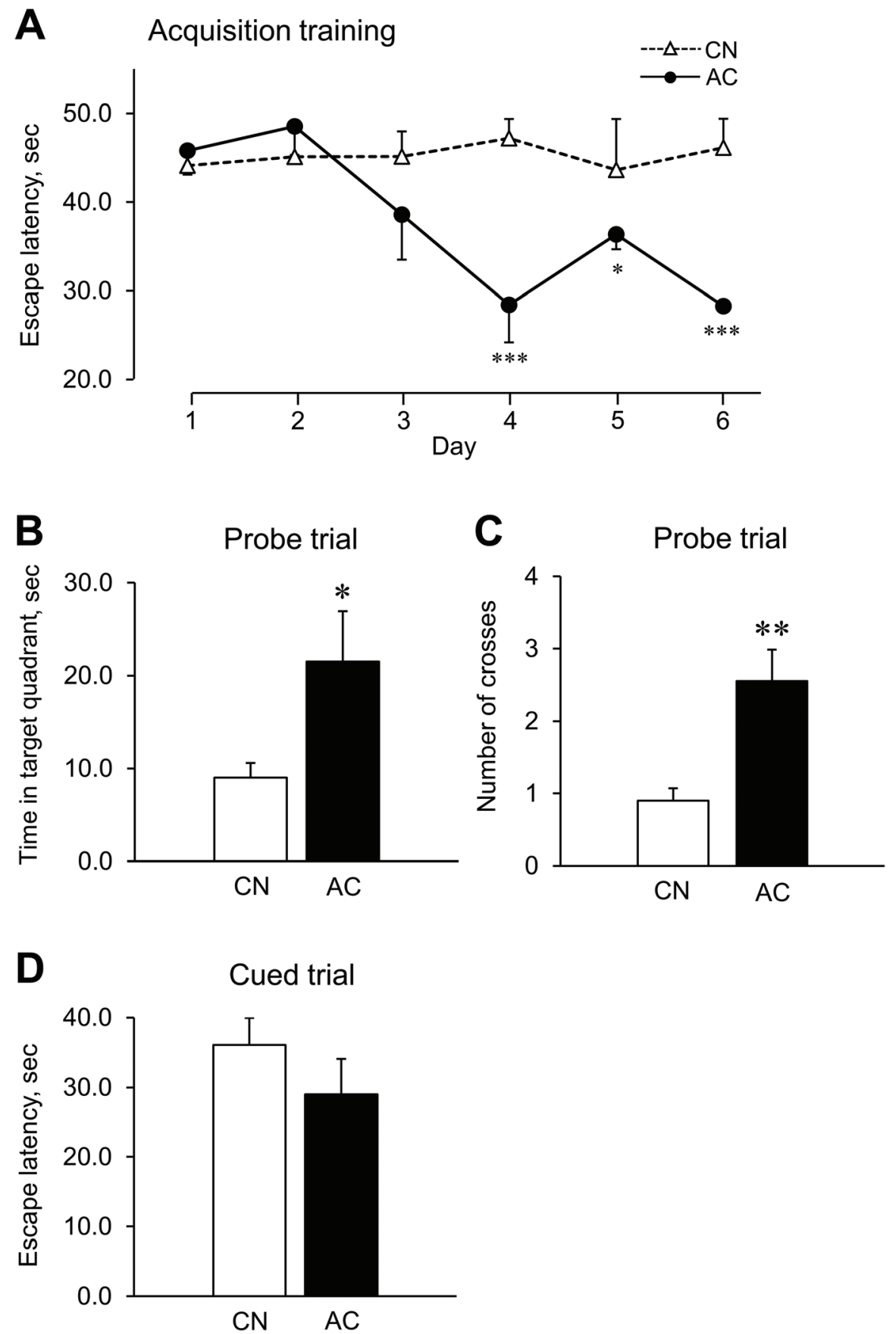

Fig. 2 Acquisition training, probe trial, and cued trial in the Morris Water Maze (MWM) task. (A) Escape latencies during the acquisition training (hidden platform) for 6 consecutive days. Mice were given three trials per day, and data represent the mean and SE of blocks of three trials. (B) Time spent in the target quadrant and (C) the number of platform-site crossovers during the probe trial (removed platform) on day 7. (D) Escape latency during the cued trial (visible platform) on day 8. Graphs indicate mean \pm SEM for $10 \mathrm{CN}$ and 9 AC mice. ${ }^{*} p<0.05,{ }^{* *} p<0.01,{ }^{* *} p<0.001$ compared to the CN group.

differences in the behavioral data of the acquisition training [group $\times$ day] (Fig. 2A), followed by the Tukey-Kramer post hoc test. A standard regression analysis was performed (Fig. 4A and B). Analyses were performed using SPSS Statistics version 23 (IBM Corp., Armonk, NY, USA). $p$-Values $<0.05$ were considered to be statistically significant.

\section{Results}

Table 1 shows the BWs and water and food consumption during the intervention period for the $\mathrm{AC}$ and $\mathrm{CN}$ groups. There were no significant differences between the groups with respect to $\mathrm{BW}[F(4,68)=1.23, p=0.31]$, water consumption $[F$ 
A

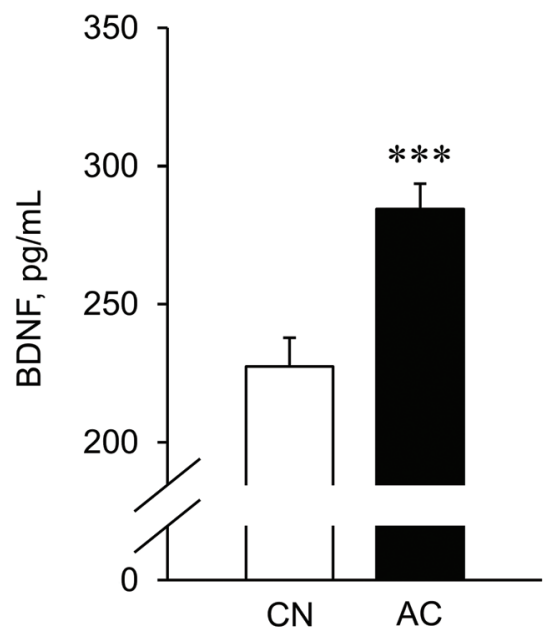

C

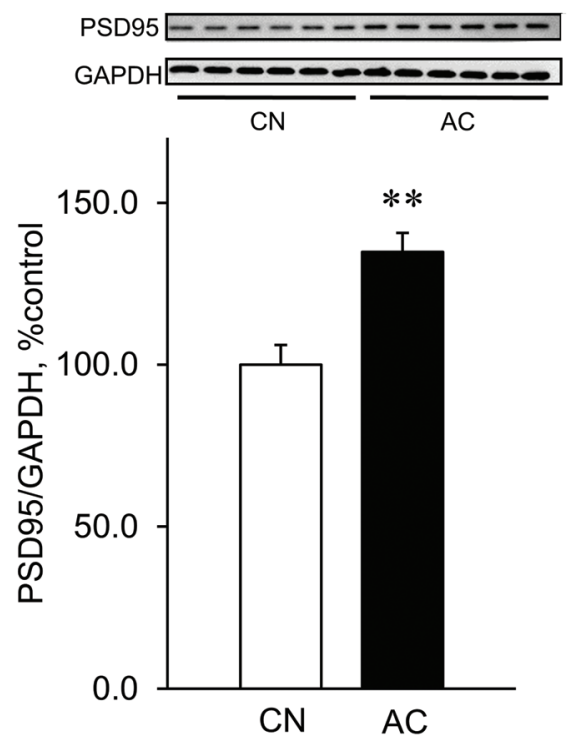

B
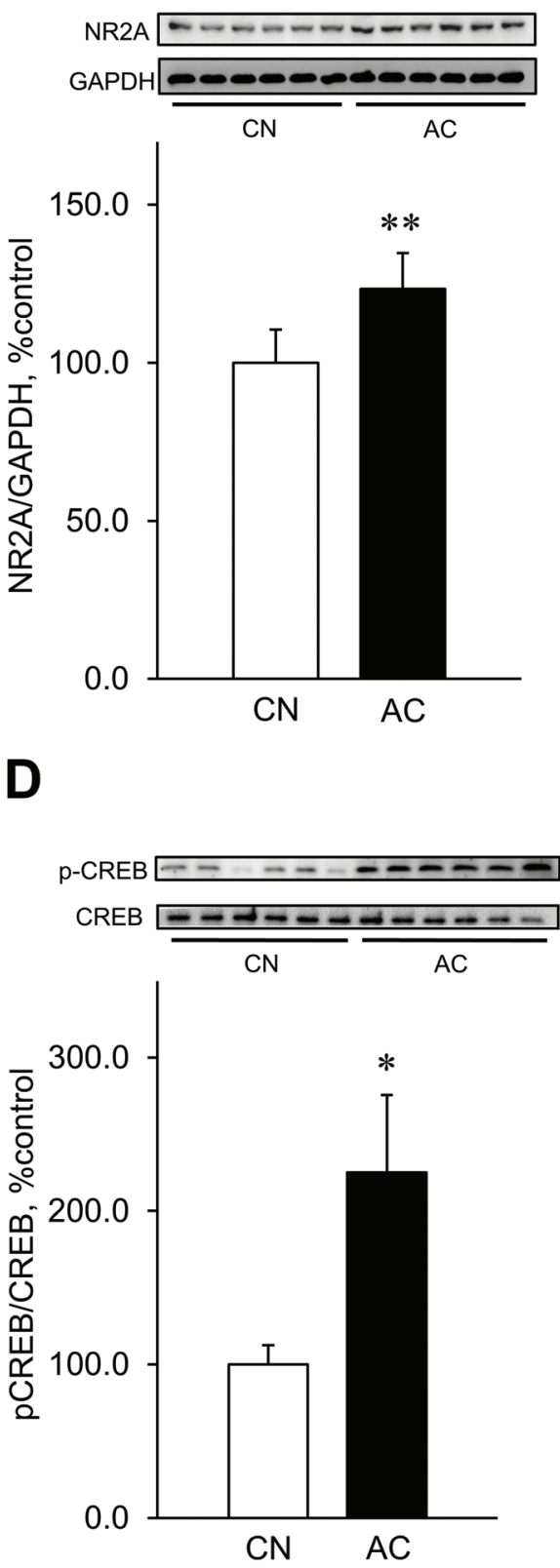

Fig. 3 (A) Levels of brain-derived neurotropic factor (BDNF), (B) NMDA-receptor (NMDAR) subunit NR2A, (C) postsynaptic density protein-95 (PSD95), and (D) levels of transcription factor CAMP-response element binding (CREB) in the hippocampus of AC and CN group SAMP8 mice, respectively. Data indicate mean \pm SEM for $10 \mathrm{CN}$ and $9 \mathrm{AC}$ mice. ${ }^{*} p<0.05,{ }^{* *} p<0.01,{ }^{* *} p<0.001$, compared to the CN group.

$(3,51)=1.43, p=0.24]$, or food consumption $[F(3,51)=0.49$, $p=0.69]$ throughout the intervention period. The liver weight (mg $\mathrm{g}^{-1} \mathrm{BW}$ ), kidney weight ( $\mathrm{mg} \mathrm{\textrm {g } ^ { - 1 }}$ BW) and heart weight $\left(\mathrm{mg} \mathrm{g}^{-1}\right.$ BW) did not vary between the groups (data not shown).

Table 2 shows the blood biochemistry of the AC and $\mathrm{CN}$ groups. Oral administration of AC extract did not affect the blood cell counts and the levels of hemoglobin, hematocrit, or platelets compared to the $\mathrm{CN}$ group. Likewise, the effects of AC extract on the lipid profile and hepatorenal function markers were not statistically different between the two groups.

To determine the effects of AC extract on learning and memory, we analyzed SAMP8 mice performing the NOR task (Fig. 1). In the familiarization session, mice of both the AC and $\mathrm{CN}$ groups spent similar amounts of time exploring objects A1 and A2 [AC: $t(8)=1.82, p=0.11$; CN: $t(9)=2.24, p$ $=0.052]$ (Fig. 1A). Consequently, the DI was not significantly 
Table 1 Body weights and food and water consumption during the intervention period of control (CN) and Anredera cordifolia extract (AC) treated SAMP8 mice

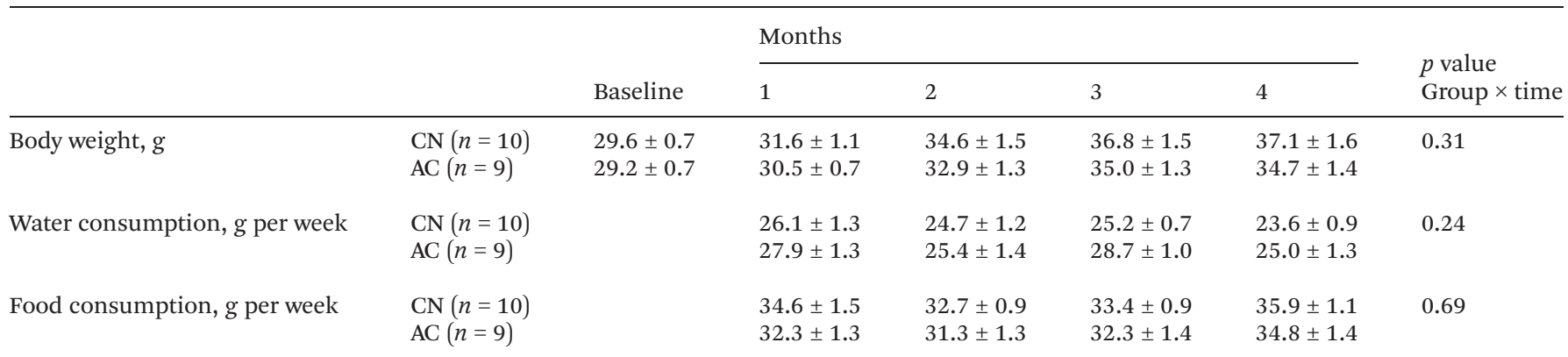

Values are expressed as mean $\pm \mathrm{SE}$.

\section{A}

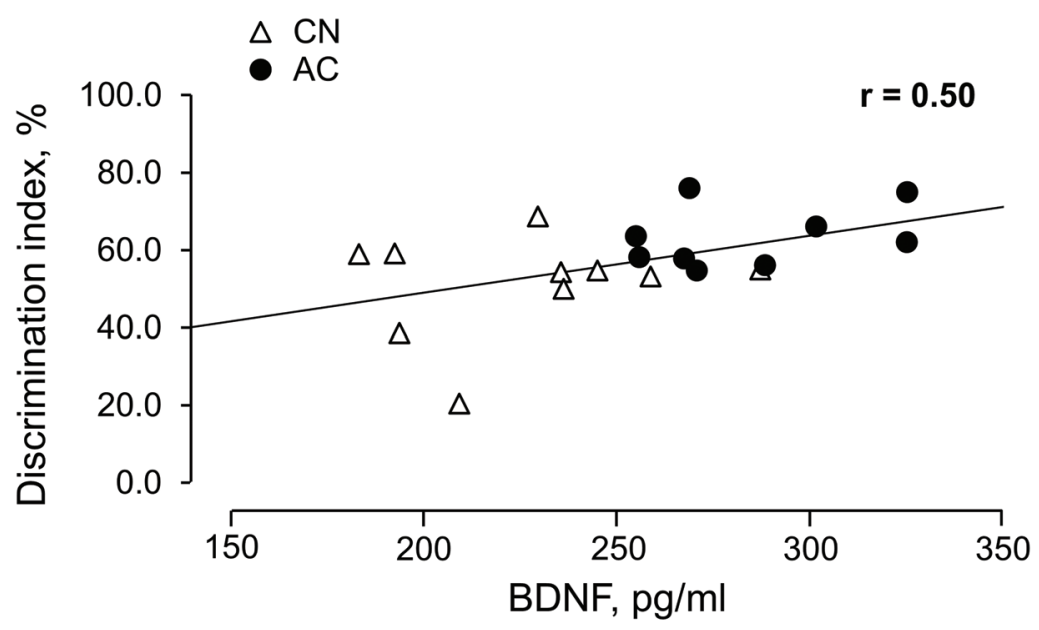

B

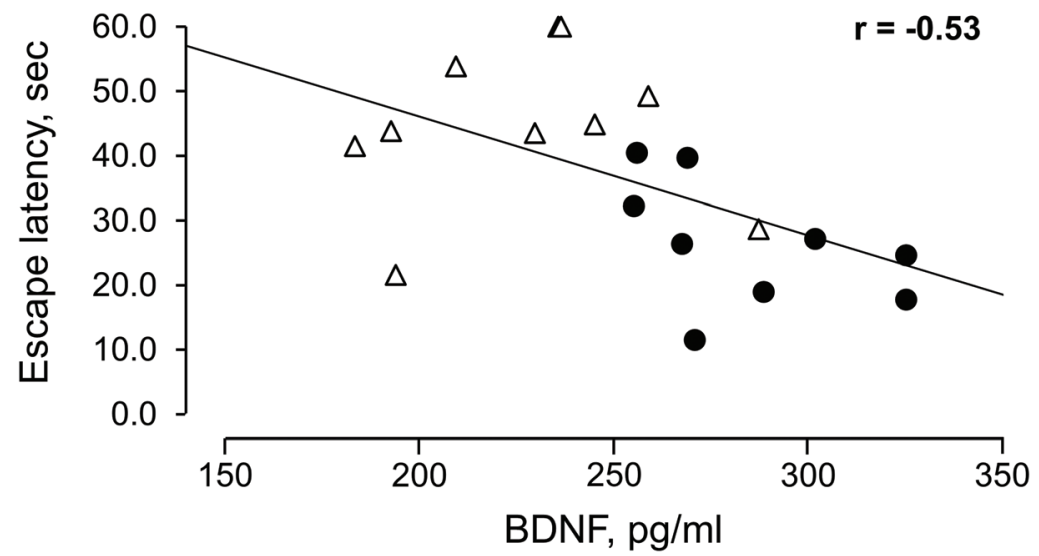

Fig. 4 Relationship between the hippocampal BDNF and (A) the DIs of the test session in the NOR task, and (B) the escape latencies on day 6 of the acquisition training in the MWM task. Individual values of 19 mice (10 CN and 9 AC group mice) are shown. Discrimination index, escape latencies on day 6, and hippocampal BDNF levels are the same as data shown in Fig. 1D, 2A, and 3A, respectively. 
Table 2 Blood biochemistry parameters of control (CN) and Anredera cordifolia extract (AC) treated SAMP8 mice

\begin{tabular}{|c|c|c|c|}
\hline Parameters & $\mathrm{CN}(n=10)$ & $\mathrm{AC}(n=9)$ & $p$ value \\
\hline WBC, $\times 10^{2} \mu \mathrm{L}^{-1}$ & $23.6 \pm 2.0$ & $26.5 \pm 1.8$ & 0.30 \\
\hline $\mathrm{RBC}, \times 10^{4} \mu \mathrm{L}^{-1}$ & $754.0 \pm 18.2$ & $768.8 \pm 15.2$ & 0.55 \\
\hline $\mathrm{HGB}, \mathrm{g} \mathrm{dL} \mathrm{L}^{-1}$ & $11.8 \pm 0.3$ & $12.1 \pm 0.3$ & 0.59 \\
\hline HCT, \% & $38.2 \pm 1.0$ & $39.1 \pm 0.8$ & 0.46 \\
\hline PLT, $\times 10^{4} \mu \mathrm{L}^{-1}$ & $12.6 \pm 3.1$ & $17.8 \pm 2.9$ & 0.24 \\
\hline HDL-C, $\mathrm{mg} \mathrm{dL} \mathrm{dL}^{-1}$ & $55.4 \pm 1.6$ & $53.9 \pm 2.4$ & 0.59 \\
\hline $\mathrm{TG}, \mathrm{mg} \mathrm{dL^{-1 }}$ & $126.8 \pm 11.6$ & $116.0 \pm 16.0$ & 0.59 \\
\hline GOT, IU L ${ }^{-1}$ & $24.7 \pm 3.8$ & $27.2 \pm 4.9$ & 0.68 \\
\hline $\mathrm{GPT}, \mathrm{IU} \mathrm{L}^{-1}$ & $15.8 \pm 6.2$ & $15.4 \pm 6.3$ & 0.97 \\
\hline$\gamma$-GTP, IU L ${ }^{-1}$ & $2.6 \pm 0.5$ & $1.9 \pm 0.1$ & 0.29 \\
\hline T-Cho, $\mathrm{mg} \mathrm{dL}^{-1}$ & $86.0 \pm 2.8$ & $83.2 \pm 3.2$ & 0.51 \\
\hline $\mathrm{TP}, \mathrm{g} \mathrm{dL}^{-1}$ & $3.9 \pm 0.1$ & $4.0 \pm 0.1$ & 0.36 \\
\hline $\mathrm{Alb}, \mathrm{g} \mathrm{dL}^{-1}$ & $1.8 \pm 0.1$ & $1.8 \pm 0.1$ & 0.35 \\
\hline BUN, mg dL $\mathrm{dL}^{-1}$ & $24.7 \pm 1.0$ & $26.6 \pm 2.6$ & 0.49 \\
\hline Uric acid, $\mathrm{mg} \mathrm{dL} \mathrm{d}^{-1}$ & $0.9 \pm 0.1$ & $0.9 \pm 0.1$ & 0.92 \\
\hline Creatinine, $\mathrm{mg} \mathrm{dL}^{-1}$ & $0.2 \pm 0.0$ & $0.2 \pm 0.0$ & 0.99 \\
\hline
\end{tabular}

Values indicate mean \pm SE of duplicate determinations. WBC, white blood cell; RBC, red blood cell; HGB, hemoglobin; HCT, hematocrit; PLT, platelet; HDL-C, high-density lipoprotein cholesterol; TG, triglyceride; GOT, glutamate oxaloacetate transaminase; GPT, glutamic pyruvic transaminase; $\gamma$-GTP, $\gamma$-glutamyl transpeptidase; T-Cho, total cholesterol; TP, total protein; Alb, albumin; BUN, blood urea nitrogen

different between the groups $[t(17)=0.47, p=0.64]$ (Fig. 1B). During the test session, the mice in the AC group spent significantly more time exploring the novel object (B) than the familiar object (A1) $[t(8)=3.79, p=0.005]$. However, the mice in the $\mathrm{CN}$ group did not display any significant difference in the exploration time between the objects $[t(9)=0.47, p=0.65]$ (Fig. 1C). Consequently, the DI was significantly higher in the AC group than in the $\mathrm{CN}$ group $[t(17)=2.36, p=0.030]$ (Fig. 1D).

We also sought to determine the effect of AC extract on the locomotor activity of SAMP8 mice. The total distance traveled by mice in the AC group $(491.8 \pm 67.4 \mathrm{~cm})$ was not significantly different from that traveled by those in the $\mathrm{CN}$ group $(397.8 \pm$ $28.3 \mathrm{~cm} ; t(17)=1.29, p=0.23)$.

The effects of AC extract on spatial learning and memory was quantified by the mean escape latency during acquisition training of the MWM task (Fig. 2A). There was a significant interactive effect observed between the groups and the days of the acquisition training $[F(5,85)=4.31, p=0.002]$; mice in the AC group were confirmed to outperform the $\mathrm{CN}$ group mice on days 4,5 and $6(p<0.05)$, but the two groups performed similarly on days 1,2 and $3(p>0.05)$. These results suggest that the $\mathrm{AC}$ group had greater learning ability than the $\mathrm{CN}$ group. To evaluate reference memory, we performed a probe trial $24 \mathrm{~h}$ after the last acquisition trial. If the memory of the acquisition training of a mouse remained stable, i.e., if the spatial learning for the location of the escape platform was accurate, the mouse would easily swim to the previous location of the platform and/or navigate around the previous exact location. Therefore, the more accurate the spatial memory is, the greater the frequency of the mouse swimming across the escape platform and/or near the previous location of the platform. We found that the time spent in the target quadrant by the $\mathrm{AC}$ group was significantly longer than that by the $\mathrm{CN}$ group $[t$ $(17)=2.47, p=0.025$ ] (Fig. 2B). Similarly, the number of platform-site crossovers by the AC group was significantly higher than that by the CN group $[t(17)=3.40, p=0.003]$ (Fig. 2C). There was no significant difference between the escape latencies of the AC and $\mathrm{CN}$ groups during the cued trial $[t$ (17) $=0.96, p=0.35$ ] (Fig. 2D). From these results, we concluded that the swimming ability of both groups was equivalent, but the learning ability and reference memory of the $\mathrm{AC}$ group were superior to those of the $\mathrm{CN}$ group.

To determine the effect of oral administration of AC extract on the levels of BDNF, NR2A, and PSD95 proteins and on p-CREB/CREB ratio, we performed ELISA and western blot assays. Administration of $\mathrm{AC}$ extract led to a significant increase in the levels of BDNF by 25.1\% $[t(17)=4.10, p=$ $0.0008]$ (Fig. 3A), NR2A by 23.4\% $[t(17)=3.84, p=0.0013]$ (Fig. 3B), and PSD95 by $34.8 \%[t(17)=3.87, p=0.0012]$ (Fig. 3C), and the p-CREB/CREB ratio by $125.0 \%[t(17)=2.40$, $p=0.040]$ (Fig. 3D) in hippocampal tissues compared to those in the $\mathrm{CN}$ group.

We also investigated the relationship between the levels of BDNF in the hippocampus and performance in the learning and memory tasks. A regression analysis was performed between the hippocampal BDNF levels and the DIs of the test session in the NOR task (Fig. 4A). A significant positive correlation was observed between the hippocampal BDNF levels and the DIs $[r=0.50, p=0.030]$. Similarly, a regression analysis was performed between the hippocampal BDNF levels and the escape latencies on day 6 in the acquisition training (Fig. 4B), and a significant negative correlation was observed $[r=-0.53$, $p=0.019]$.

\section{Discussion}

The results of the current investigation clearly suggest that oral administration of AC extract significantly increased the learning ability and memory of SAMP8 mice. The amelioration of learning and memory decline in these mice was accompanied by an increase in the levels of neuronal plasticity-related proteins BDNF, PSD95, and NR2A, and the phosphorylation of CREB in the brain hippocampus. Moreover, AC extract did not exhibit any deleterious side effects on the hepatorenal structures or functions, as indicated by the lack of significant changes in the hepatorenal markers in AC-treated mice. The lipid profiles and hematological parameters also were not remarkably different between the $\mathrm{AC}$ and $\mathrm{CN}$ groups (Table 2). These results demonstrate that AC plant extract used in the present investigation had no baleful effect on the blood biochemical parameters or survival of SAMP8 mice. We therefore evaluated the effect of oral administration of AC extract on learning and memory in SAMP8 mice via the NOR and MWM task paradigms.

The NOR task evaluates the rodents' ability to recognize a novel object in the environment. ${ }^{44}$ The dorsal hippocampus 
plays an important role in memory formation, especially when spatial or contextual information is a relevant factor, as in the NOR task. ${ }^{45}$ The total time spent exploring the novel object in the test session by the AC group mice significantly increased compared to that spent exploring the familiar object. On the other hand, there was no significant difference in the time spent exploring the objects by mice in the $\mathrm{CN}$ group. These results indicated that the memory formed in the familiarization session was retained for at least 24 hours in the AC group. Thus, the learning and memory effects of AC extract may be due to its beneficial influence on the hippocampus.

In the MWM task, a lower score in the escape latency is used as an index of enhanced spatial learning and memory. ${ }^{23}$ In the present experiments, the $\mathrm{AC}$ group displayed significantly decreased escape latencies as compared to the $\mathrm{CN}$ group. The shorter escape latencies suggest that oral administration of AC extract significantly accelerated the acquisition of information concerning spatial environments in the brain hippocampus. The increased "acquisition ability" (i.e., ability to process information on their surroundings) thus enabled the AC group to retain the memory and perform better during the probe trial (memory retention test). This was indicated by the time spent in the target quadrant and the number of crossover events during the probe trial. In other words, the SAMP8 mice that chronically ingested AC extract prevailed over the control mice in recalling the previous spatial location of the hidden platform.

Prior to the MWM task, we evaluated the behavior of the SAMP8 mice in the non-aversive open-field task. The measures of total distance traveled were not significantly different between the $\mathrm{AC}$ and $\mathrm{CN}$ groups. The $\mathrm{AC}$ extract at the given dose did not have an effect on motor coordination. Moreover, escape latencies during the acquisition training or probe test are likely to be affected by the swimming (motor) ability, especially when the animals belong to an accelerated agingsenescence model with compromised physical strength. However, in the cued trial, where memory cognition is not involved, the escape latency was not significantly different between the groups, suggesting that performance during the acquisition training and the probe trial in the MWM task were not related to the physical strength of the SAMP8 mice. Together, the results of the open-field test and the cued trial ruled out the possibility that the shorter escape latencies shown by the AC group were due to the effects of the AC extract on the locomotor activities and/or physical strength during swimming. Rather, the AC extract improved the spatial learning ability and memory of the mice. Therefore, the escape latencies to reach the previous hidden-platform location were reduced in the $\mathrm{AC}$ group compared to those in the $\mathrm{CN}$ group. We speculate that the beneficial effects of AC extract on spatial learning and memory are due to its effects on the brain, and in particular, the hippocampus.

The enhancement in learning and memory in the AC group is correlated with significant increases in the protein levels of BDNF, PSD95, and the NR2A subunit of NMDARs, as well as the phosphorylation of CREB in the hippocampus. The signals mediated by these proteins are critical to neurogenesis, synaptogenesis, and formation and retention of memory in the hippocampus. ${ }^{46}$ Therefore, increases in the levels of these proteins may contribute to increased molecular signaling, and subsequently to improvements in learning and memory in the SAMP8 mice in the NOR and MWM tasks. Notably, a decrease in the levels and/or functional impairments of these signaling proteins may cause memory deficits in the SAMP8 mice. For example, BDNF has enormous effects on the modulation of synaptic plasticity. The binding of BDNF to its receptor TrkB results in the activation of various downstream signaling pathways ${ }^{47}$ involved in the modulation of synapses, synaptic plasticity, and behavior. ${ }^{48,49}$ Specifically, BDNF colocalizes with its receptor (TrkB) at glutamatergic presynaptic and postsynaptic terminals. It has been reported that activation of BDNF-TrkB signaling modulates presynaptic glutamate release in the hippocampus. ${ }^{50,51}$ Therefore, we infer that increased BDNF levels in the hippocampus of the AC group play a significant role in glutamatergic signaling, particularly in the formation of LTP. The basis of this speculation emerged from evidence showing that the impairment of LTP in BDNF-knockout mice could be recovered by an acute application of $\mathrm{BDNF},{ }^{52-54}$ and in situ application of BDNF to hippocampal slice induced synaptic potentiation. ${ }^{55,56}$ Still, the mechanism(s) by which AC extract-induced increases in hippocampal BDNF would instigate LTP formation requires clarification.

BDNF can induce LTP, which is a neurochemical response that signals to numerous downstream pathways. ${ }^{55,57,58}$ Accumulating evidence suggests that BDNF affects glutamate AMPA receptors and NMDARs. The glutamate receptor might be one of the targets of AC extract leading to the modulation of synaptic plasticity. Numerous studies have shown that BDNF at the post-synapse promotes the expression and insertion of inotropic glutamate AMPA-receptors (AMPARs) in hippocampal neurons. ${ }^{59,60}$ Oral administration of AC extract significantly increased the levels of the NR2A subunit of NMDARs in the hippocampus of SPAM8 mice in the current study. It has been reported that BDNF increased the levels of both NR2A and NR2B subunits in cultured hippocampal neurons, ${ }^{59}$ these subunits being the dominant forms found in the rodent hippocampus. ${ }^{61,62}$ We therefore propose that AC extract contributes to synaptic modulation/plasticity and increases learning and memory in SAMP8 mice by increasing NR2A-dependent NMDAR signaling.

Whatever the mechanism, BDNF-dependent LTP and synaptic plasticity in the hippocampus of SAMP8 mice would involve signaling downstream of the BDNF-NR2A interaction. At this stage, it is possible that PSD95 could be a target of NMDAR signaling due to the complex association of NMDARs and PSD95 implicated in the regulation of synaptic modulation/ plasticity, learning, and memory. ${ }^{63}$ Interestingly, the AC extract significantly increased the hippocampal levels of PSD95. It has been reported that the subunits of the synaptic NMDARs remain highly organized and spatially restricted in the postsynaptic densities (PSDs) within the postsynaptic membrane. ${ }^{64}$ 
Usually, PSD95 targets the NR2A and NR2B subunits of NMDAR, and acts as an anchoring/scaffolding and adaptor protein. ${ }^{61,63}$ Therefore, PSD95 stimulates the neuronal plasma membrane assembly of NMDARs, enhances NMDA-channel opening, permitting ion entry, and links the synaptic NMDARs to many other downstream signaling molecules, ${ }^{64}$ ultimately leading to higher synaptic activity. Therefore, the increased levels of hippocampal PSD95 in the AC group suggest that the NMDAR-PSD95 association was strengthened, which in turn activated the downstream signals in the hippocampus contributing to the enhancement of learning and memory in SAMP8 mice.

Enhanced synaptic plasticity implies that the strength of synapses is increased either by the addition of new receptors to neuronal plasma membranes, or by acceleration of the synthesis of signaling proteins to increase the synaptic activity. Increases in the levels of BDNF, NR2A, and PSD95, concurrent with the enhancement of learning and memory, were thus consistent with enhanced synaptic plasticity in the AC group. However, these increases in the protein levels of BDNF, NR2A, or PSD95 are only attainable if their transcription/translation was accelerated, perhaps dependent on CREB, an important transcription factor. Intriguingly, the transcriptional activity of CREB depends on its degree of phosphorylation, which is a key mechanism in cell signaling and is reported to regulate processes such as cell cycle, ${ }^{65}$ cell death, ${ }^{66}$ DNA damage response, ${ }^{67}$ and neurogenesis. ${ }^{68}$ Oral administration of $\mathrm{AC}$ extract significantly increased the $\mathrm{p}$-CREB/CREB ratio in the hippocampus of SAMP8 mice, demonstrating that the AC extract induced higher phosphorylation than dephosphorylation. It is thus likely that AC extract initiates translation of extracellular stimuli into p-CREB-mediated gene expression of BDNF, NR2A, and PSD95. The enhancement in learning and memory in the AC group might be related, at least partially, to its protective effects against oxidative stress. Our results indicate that enhanced cognitive functions are closely related to the improved expression of BDNF, the NR2A subunit of NMDAR, and PSD95, as well as phosphorylation of CREB in the hippocampus of AC extract-administered SAMP8 mice. However, it is unclear which component of the AC extract was effective in improving cognitive function. It has been reported that AC has high amounts of flavonoids. ${ }^{69}$ Previous studies have suggested the presence of a link between flavonoid intake and better cognitive function in humans and animals. ${ }^{70}$ Flavonoids might have been one of the effective substances that improved cognitive function in SAMP8 mice in the current study. It is also known that AC contains saponin compounds, ${ }^{69,71}$ and some of these compounds (e.g., triterpenoid saponin) have been reported to improve cognitive function. ${ }^{72}$ As such, saponins and polyphenols are key ingredients in traditional Chinese medicines. ${ }^{73}$ However, the types of flavonoids have not yet been identified and need to be investigated in the future. Furthermore, it is suggested that adenosine and its derivative, cordysinin B, might be active ingredients in AC. Further studies are necessary to clarify the compounds of AC extract.

\section{Conclusion}

The present study suggests that Anredera cordifoila extract has potent memory-enhancing effects in SAMP8 mice. These beneficial effects might result from the increased expression of BDNF, PSD95, NR2A, and p-CREB in the hippocampus of these mice. We propose that Anredera cordifoila-induced increases in the levels of BDNF stimulates multiple NMDAR-PSD95-mediated signaling pathways, increasing the levels of p-CREB, and translating the external stimuli of the spatial cues into a plastic neurocircuitry in the hippocampus. Thus, hippocampus-dependent learning and memory significantly increased in SAMP8 mice following the oral administration of AC extract. Finally, as SAMP8 mice represent a model of human $\mathrm{AD}$, our findings provide evidence that $\mathrm{AC}$ extract may be used in preventing behavioral deficits and the decrease of proteins related to learning and memory. Future research should investigate the active components (e.g., flavanols and saponins) of the AC extract. Furthermore, the molecular mechanisms underlying the cognitive enhancement associated with AC extracts should be studied using immunohistochemical staining and immunofluorescence. In addition, investigations on the effects of AC extract on human cognitive function are warranted.

\section{Author contributions}

Eri Sumiyoshi: conceptualization, data curation, formal analysis, funding acquisition, investigation, project administration, visualization, roles/writing-original draft, writingreview \& editing. Michio Hashimoto: conceptualization, funding acquisition, project administration, visualization, roles/writing-original draft, writing-review \& editing. Shahdat Hossain: data curation, investigation, methodology, visualization, roles/writing-original draft. Kentaro Matsuzaki: data curation, investigation, methodology, resources, roles/writingoriginal draft, writing-review \& editing. Rafiad Islam: data curation, investigation. Yoko Tanabe: investigation. Koji Maruyama: conceptualization, resources. Koji Kajima: conceptualization, resources. Hiroyuki Arai: conceptualization. Yasushi Ohizumi: conceptualization. Osamu Shido: conceptualization, supervision.

\section{Conflicts of interest}

The authors declare no conflicts of interest, financial or otherwise.

\section{Acknowledgements}

This research was supported by the Ministry of Education, Culture, Sports, Science, and Technology of Japan Grant-in-Aid for Young Scientists 18K17965. This research was partly supported by the Cooperative Research Project Program of Joint 
Usage/Research Center at the Institute of Development, Aging and Cancer, Tohoku University. This research was also supported by Sankyo Holdings Co., Ltd.

\section{References}

1 M. T. Chuang, Y. S. Lin and W. C. Hou, Ancordin, the major rhizome protein of madeira-vine, with trypsin inhibitory and stimulatory activities in nitric oxide productions, Peptides, 2007, 28, 1311-1316.

2 D. R. Laksmitawati, A. Widyastuti, N. Karami, E. Afifah, D. D. Rihibiha, H. Nufus and W. Widowati, Anti-inflammatory effects of Anredera cordifolia and Piper crocatum extracts on lipopolysaccharide-stimulated macrophage cell line, Bangladesh J. Pharmacol., 2017, 12, 35-40.

3 L. Wang, C. Y. Bang and S. Y. Choung, Anti-Obesity and Hypolipidemic Effects of Boussingaultia gracilis Miers var. pseudobaselloides Bailey in Obese Rats, J. Med. Food, 2011, 14, 17-25.

4 T. E. Tshikalange, J. J. M. Meyer and A. A. Hussein, Antimicrobial activity, toxicity and the isolation of a bioactive compound from plants used to treat sexually transmitted diseases, J. Ethnopharmacol., 2005, 96, 515-519.

5 A. N. Garmana, E. Y. Sukandar and I. Fidrianny, Preliminary study of blood pressure lowering effect of Anredera cordifolia (Ten) steenis on Wistar rats, Int. J. Pharm. Pharm. Res., 2016, 8, 300-304.

6 E. Y. Sukandar, A. Ridwan and Y. P. Sukmawan, Vasodilatation effect of ethanolic extract of anredera cordifolia, sonchus arvensis 1, and ursolic acid on isolated rabbit aortic and frog heart, Int. J. Pharm. Pharm. Sci., 2016, 8, 145-149.

7 W. M. Yuniarti and B. S. Lukiswanto, Effects of herbal ointment containing the leaf extracts of Madeira vine (Anredera cordifolia (Ten.) Steenis) for burn wound healing process on albino rats, Vet. World, 2017, 10, 808-813.

8 K. Maruyama, K. Arai, T. Sakakiyama, K. Yoshino and K. Kajima, Anredera cordifolia Water Extract Effectively Ameliorates Metabolic Syndrome Abnormalities in High Fructose-Fed Mouse Model, Pharmacometrics, 2014, 87(1/2), 21-24.

9 K. Maruyama, M. Yamada, K. Yamauchi, K. Yoshino and K. Kajima, Anredera cordiifolia, Water Extract Effectively Decrease in Vivo Oxidative Stress in High Fructose-Fed Mouse Model, Pharmacometrics, 2015, 88(3/4), 47-51.

10 K. Maruyama, K. Yoshino and K. Kajima, Anredera cordifolia, Ethanolic Extract Effectively Ameliorates Metabolic Syndrome in High Fructose-Fed Mouse Model, Pharmacometrics, 2016, 90(1/2), 25-30.

11 A. Nakajima, M. Hachiro, K. Kajima and Y. Ohizumi, Anredera cordifolia Extract Improves MK-801-Induced Memory Impairment in Mice, Pharmacometrics, 2020, 98, 27-30.

12 A. Nakajima, M. Kamada, M. Kawada, T. Yoshinaga, N. Uozumi, Y. Guo, K. Kajima and Y. Ohizumi, Anredera cordifolia Extract Stimulates CRE- and SRE-Mediated Transcription, and Induces c-fos Gene Expression in PC12 Cells, Pharmacometrics, 2020, 99(3/4), 45-53.

13 R. Bhat, E. P. Crowe, A. Bitto, M. Moh, C. D. Katsetos, F. U. Garcia, F. B. Johnson, J. Q. Trojanowski, C. Sell and C. Torres, Astrocyte Senescence as a Component of Alzheimer's Disease, PLoS One, 2012, 7, 10.

14 M. Moon, H. U. Jeong, J. G. Choi, S. G. Jeon, E. J. Song, S. P. Hong and M. S. Oh, Memory-enhancing effects of Cuscuta japonica Choisy via enhancement of adult hippocampal neurogenesis in mice, Behav. Brain Res., 2016, 311, 173-182.

15 P. Lu, T. Mamiya, L. Lu, A. Mouri, L. Zou, T. Nagai, M. Hiramatsu, T. Ikejima and T. Nabeshima, Silibinin prevents amyloid $\beta$ peptide-induced memory impairment and oxidative stress in mice, Br. J. Pharmacol., 2009, 157, 12701277.

16 M. Pallas, A. Camins, M. A. Smith, G. Perry, H. G. Lee and G. Casadesus, From Aging to Alzheimer's Disease: Unveiling "The Switch" with the Senescence-Accelerated Mouse Model (SAMP8), J. Alzheimer's Dis., 2008, 15, 615624.

17 M. Miyamoto, Y. Kiyota, N. Yamazaki, A. Nagaoka, T. Matsuo, Y. Nagawa and T. Takeda, AGE-RELATED-CHANGES IN LEARNING AND MEMORY IN THE SENESCENCE-ACCELERATED MOUSE (SAM), Physiol. Behav., 1986, 38, 399-406.

18 T. Takeda, M. Hosokawa and K. Higuchi, Senescence-accelerated mouse (SAM): A novel murine model of senescence, Exp. Gerontol., 1997, 32, 105-109.

19 J. Jia, L. Kang, S. Li, D. Geng, P. Fan, L. Wang and H. Cui, Amelioratory effects of testosterone treatment on cognitive performance deficits induced by soluble A $\beta 1-42$ oligomers injected into the hippocampus, Horm. Behav., 2013, 64, 477-486.

20 A. Ennaceur and J. Delacour, A new one-trial test for neurobiological studies of memory in rats. 1: Behavioral data, Behav. Brain Res., 1988, 31, 47-59.

21 N. J. Broadbent, S. Gaskin, L. R. Squire and R. E. Clark, Object recognition memory and the rodent hippocampus, Learn. Mem., 2010, 17, 794-800.

22 A. Nakajima, Y. Aoyama, T. T. Nguyen, E. J. Shin, H. C. Kim, S. Yamada, T. Nakai, T. Nagai, A. Yokosuka, Y. Mimaki, Y. Ohizumi and K. Yamada, Nobiletin, a citrus flavonoid, ameliorates cognitive impairment, oxidative burden, and hyperphosphorylation of tau in senescenceaccelerated mouse, Behav. Brain Res., 2013, 250, 351-360.

23 R. Morris, An attempt to dissociate "spatial-mapping and working-memory" theories of hippocampal function, in The Neurobiology of the hippocampus, ed. W. Seifert, 1983, Academic Press, London, pp. 405-432.

24 S. Yanai and S. Endo, Early onset of behavioral alterations in senescence-accelerated mouse prone 8 (SAMP8), Behav. Brain Res., 2016, 308, 187-195.

25 R. G. M. Morris, S. Davis and S. P. Butcher, HIPPOCAMPAL SYNAPTIC PLASTICITY AND NMDA RECEPTORS - A ROLE 
IN INFORMATION-STORAGE, Philos. Trans. $R$. Soc., B, 1990, 329, 187-204.

26 K. B. Baker and J. J. Kim, Effects of stress and hippocampal NMDA receptor antagonism on recognition memory in rats, Learn. Mem., 2002, 9, 58-65.

27 J. C. Lopez-Ramos, M. T. Jurado-Parras, C. Sanfeliu, D. Acuna-Castroviejo and J. M. Delgado-Garcia, Learning capabilities and CA1-prefrontal synaptic plasticity in a mice model of accelerated senescence, Neurobiol. Aging, 2012, 33(627), e13-e26.

28 T. Takeuchi, A. J. Duszkiewicz and R. G. M. Morris, The synaptic plasticity and memory hypothesis: encoding, storage and persistence, Philos. Trans. R. Soc., B, 2014, 369, 20130288.

29 S. Taniguchi, H. Mizuno, M. Kuwahara and K. Ito, Early attenuation of long-term potentiation in senescence-accelerated mouse prone 8, Exp. Brain Res., 2015, 233, 31453152.

30 R. Corpas, A. M. Hernandez-Pinto, D. Porquet, C. Hernandez-Sanchez, F. Bosch, A. Ortega-Aznar, F. Comellas, E. J. de la Rosa and C. Sanfeliu, Proinsulin protects against age-related cognitive loss through antiinflammatory convergent pathways, Neuropharmacology, 2017, 123, 221-232.

31 M. Dobarro, L. Orejana, N. Aguirre and M. J. Ramírez, Propranolol restores cognitive deficits and improves amyloid and Tau pathologies in a senescenceaccelerated mouse model, Neuropharmacology, 2013, 64, 137-144.

32 M. Tajes, J. Gutierrez-Cuesta, J. Folch, D. Ortuno-Sahagun, E. Verdaguer, A. Jimenez, F. Junyent, A. Lau, A. Camins and M. Pallas, Neuroprotective role of intermittent fasting in senescence-accelerated mice P8 (SAMP8), Exp. Gerontol., 2010, 45, 702-710.

33 Q. Li, H. Zhao, Z. Zhang, Z. Liu, X. Pei, J. Wang and Y. Li, Long-term green tea catechin administration prevents spatial learning and memory impairment in senescenceaccelerated mouse prone- 8 mice by decreasing A $\beta 1-42$ oligomers and upregulating synaptic plasticity-related proteins in the hippocampus, Neuroscience, 2009, 163, 741749.

34 N. Lin, X. D. Pan, A. Q. Chen, Y. G. Zhu, M. Wu, J. Zhang and X. C. Chen, Tripchlorolide improves ageassociated cognitive deficits by reversing hippocampal synaptic plasticity impairment and NMDA receptor dysfunction in SAMP8 mice, Behav. Brain Res., 2014, 258, 8-18.

35 R. S. Hammond, L. E. Tull and R. W. Stackman, On the delay-dependent involvement of the hippocampus in object recognition memory, Neurobiol. Learn. Mem., 2004, 82, 2634.

36 R. Islam, K. Matsuzaki, E. Sumiyoshi, M. E. Hossain, M. Hashimoto, M. Katakura, N. Sugimoto and O. Shido, Theobromine Improves Working Memory by Activating the CaMKII/CREB/BDNF Pathway in Rats, Nutrients, 2019, 11, 888 .
37 R. E. Clark, S. M. Zola and L. R. Squire, Impaired recognition memory in rats after damage to the hippocampus, J. Neurosci., 2000, 20, 8853-8860.

38 C. V. Vorhees and M. T. Williams, Morris water maze: procedures for assessing spatial and related forms of learning and memory, Nat. Protoc., 2006, 1, 848-858.

39 Y. Okaichi, Y. Ishikura, K. Akimoto, H. Kawashima, Y. Toyoda-Ono, Y. Kiso and H. Okaicho, Arachidonic acid improves aged rats' spatial cognition, Physiol. Behav., 2005, 84, 617-623.

40 K. Matsuzaki, M. Katakura, N. Sugimoto, T. Hara, M. Hashimoto and O. Shido, Neural progenitor cell proliferation in the hypothalamus is involved in acquired heat tolerance in long-term heat-acclimated rats, PLoS One, 2017, 12, e0178787.

41 K. Matsuzaki, T. Yamakuni, M. Hashimoto, A. M. Haque, O. Shido, Y. Mimaki, Y. Sashida and A. Ohizumi, Nobiletin restoring beta-amyloid-impaired CREB phosphorylation rescues memory deterioration in Alzheimer's disease model rats, Neurosci. Lett., 2006, 400, 230-234.

42 H. Onozuka, A. Nakajima, K. Matsuzaki, R. W. Shin, K. Ogino, D. Saigusa, N. Tetsu, A. Yokosuka, Y. Sashida, Y. Mimaki, T. Yamakuni and Y. Ohizumi, Nobiletin, a citrus flavonoid, improves memory impairment and Abeta pathology in a transgenic mouse model of Alzheimer's disease, J. Pharmacol. Exp. Ther., 2008, 326, 739-744.

43 M. Yoneda, N. Sugimoto, M. Katakura, K. Matsuzaki, H. Tanigami, A. Yachie, T. Ohno-Shosaku and O. Shido, Theobromine up-regulates cerebral brain-derived neurotrophic factor and facilitates motor learning in mice, J. Nutr. Biochem., 2017, 39, 110-116.

44 M. Antunes and G. Biala, The novel object recognition memory: neurobiology, test procedure, and its modifications, Cogn. Process., 2012, 13, 93-110.

45 M. N. de Lima, T. Luft, R. Roesler and N. Schröder, Temporary inactivation reveals an essential role of the dorsal hippocampus in consolidation of object recognition memory, Neurosci. Lett., 2006, 405, 142-146.

46 C. Cunha, R. Brambilla and K. L. Thomas, A simple role for BDNF in learning and memory?, Front. Mol. Neurosci., 2010, 3, 1 .

47 P. Ernfors and C. R. Bramham, The coupling of a trkB tyrosine residue to LTP, Trends Neurosci., 2003, 26, 171-173.

48 P. Bekinschtein, M. Cammarota, I. Izquierdo and J. H. Medina, BDNF and memory formation and storage, Neuroscientist, 2008, 14, 147-156.

49 L. Minichiello, TrkB signalling pathways in LTP and learning, Nat. Rev. Neurosci., 2009, 10, 850-860.

50 B. Mellstrom, B. Torres, W. A. Link and J. R. Naranjo, The BDNF gene: exemplifying complexity in Ca 2+-dependent gene expression, Crit. Rev. Neurobiol., 2004, 16, 43-49.

51 H. Yano, I. Ninan, H. Zhang, T. A. Milner, O. Arancio and M. V. Chao, BDNF-mediated neurotransmission relies upon a myosin VI motor complex, Nat. Neurosci., 2006, 9, 10091018. 
52 A. Figurov, L. D. PozzoMiller, P. Olafsson, T. Wang and B. Lu, Regulation of synaptic responses to high-frequency stimulation and LTP by neurotrophins in the hippocampus, Nature, 1996, 381, 706-709.

53 S. L. Patterson, T. Abel, T. A. S. Deuel, K. C. Martin, J. C. Rose and E. R. Kandel, Recombinant BDNF rescues deficits in basal synaptic transmission and hippocampal LTP in BDNF knockout mice, Neuron, 1996, 16, 11371145.

54 L. D. Pozzo-Miller, W. Gottschalk, L. Zhang, K. McDermott, J. Du, R. Gopalakrishnan, C. Oho, Z. H. Sheng and B. Lu, Impairments in high-frequency transmission, synaptic vesicle docking, and synaptic protein distribution in the hippocampus of BDNF knockout mice, J. Neurosci., 1999, 19, 4972-4983.

$55 \mathrm{H}$. J. Kang and E. M. Schuman, LONG-LASTING NEUROTROPHIN-INDUCED ENHANCEMENT OF SYNAPTIC TRANSMISSION IN THE ADULT HIPPOCAMPUS, Science, 1995, 267, 1658-1662.

56 H. J. Kang and E. M. Schuman, A requirement for local protein synthesis in neurotrophin-induced hippocampal synaptic plasticity, Science, 1996, 273, 1402-1406.

57 Y. Akaneya, T. Tsumoto, S. Kinoshita and H. Hatanaka, Brain-derived neurotrophic factor enhances long-term potentiation in rat visual cortex, J. Neurosci., 1997, 17, 6707-6716.

58 K. W. Kafitz, C. R. Rose, H. Thoenen and A. Konnerth, Neurotrophin-evoked rapid excitation through TrkB receptors, Nature, 1999, 401, 918-921.

59 M. V. Caldeira, C. V. Melo, D. B. Pereira, R. Carvalho, S. S. Correia, D. S. Backos, A. L. Carvalho, J. A. Esteban and C. B. Duarte, Brain-derived neurotrophic factor regulates the expression and synaptic delivery of alpha-amino-3hydroxy-5-methyl-4-isoxazole propionic acid receptor subunits in hippocampal neurons, J. Biol. Chem., 2007, 282, 12619-12628.

60 L. Slipczuk, P. Bekinschtein, C. Katche, M. Cammarota, I. Izquierdo and J. H. Medina, BDNF Activates mTOR to Regulate GluR1 Expression Required for Memory Formation, PLoS One, 2009, 4, e6007.

61 R. A. Al-Hallaq, T. P. Conrads, T. D. Veenstra and R. J. Wenthold, NMDA di-heteromeric receptor populations and associated proteins in rat hippocampus, J. Neurosci., 2007, 27, 8334-8343.

62 S. J. Coultrap, K. M. Nixon, R. M. Alvestad, C. F. Valenzuela and M. D. Browning, Differential expression of NMDA receptor subunits and splice variants among the CA1, CA3 and dentate gyrus of the adult rat, Mol. Brain Res., 2005, 135, 104-111.

63 P. E. Chen and D. J. A. Wyllie, Pharmacological insights obtained from structure-function studies of ionotropic glutamate receptors, Br. J. Pharmacol., 2006, 147, 839-853.

64 C. G. Lau and R. S. Zukin, NMDA receptor trafficking in synaptic plasticity and neuropsychiatric disorders, Nat. Rev. Neurosci., 2007, 8, 413-426.

65 P. D. Liu, M. Begley, W. Michowski, H. Inuzuka, M. Ginzberg, D. M. Gao, P. L. Tsou, W. J. Gan, A. Papa, B. M. Kim, L. X. Wan, A. Singh, B. Zhai, M. Yuan, Z. W. Wang, S. P. Gygi, T. H. Lee, K. P. Lu, A. Toker, P. P. Pandolfi, J. M. Asara, M. W. Kirschner, P. Sicinski, L. Cantley and W. Y. Wei, Cell-cycle-regulated activation of Akt kinase by phosphorylation at its carboxyl terminus, Nature, 2014, 508, 541-545.

66 L. J. Martin, Mitochondrial and cell death mechanisms in neurodegenerative diseases, Pharmaceuticals, 2010, 3, 839915.

67 C. M. Abreu, R. Kumar, D. Hamilton, A. W. Dawdy, K. Creavin, S. Eivers, K. Finn, J. L. Balsbaugh, R. O'Connor, P. A. Kiely, J. Shabanowitz, D. F. Hunt, M. Grenon and N. F. Lowndes, Site-Specific Phosphorylation of the DNA Damage Response Mediator Rad9 by Cyclin-Dependent Kinases Regulates Activation of Checkpoint Kinase 1, PLoS Genet., 2013, 9, 18.

68 R. Faigle and H. J. Song, Signaling mechanisms regulating adult neural stem cells and neurogenesis, Biochim. Biophys. Acta Gen. Subj., 2013, 1830, 2435-2448.

69 S. M. Astuti, M. Sakinah, R. Andayani and A. Risch, Determination of Saponin Compound from Anredera cordifolia (Ten) Steenis Plant (Binahong) to Potential Treatment for Several Diseases, J. Agric. Sci., 2011, 3(4), 224-232.

70 J. P. E. Spencer, Flavonoids: modulators of brain function?, Br. J. Nutr., 2008, 99, ES60-ES77.

71 A. Espada, J. Rodriguez, M. C. Villaverde and R. Riguera, HYPOGLYCEMIC TRITERPENOID SAPONINS FROM BOUSSINGAULTIA-BASELLOIDES, Can. J. Chem., 1990, 68, 2039-2044.

72 G. Jin, L. Zhu, P. Liu, Q. Xu, Y. Qi, X. Y. Zhou, J. K. Xu, X. F. Ji, T. Y. Chi and L. B. Zou, Xanthoceraside prevented synaptic loss and reversed learning-memory deficits in APP/PS1 transgenic mice, J. Physiol. Sci., 2019, 69, 477-488.

73 J. Liu and T. Henkel, Traditional Chinese medicine (TCM): are polyphenols and saponins the key ingredients triggering biological activities?, Curr. Med. Chem., 2002, 9, 14831485. 